\title{
Birthweight-specific risk factors for necrotising enterocolitis
}

\author{
S R PALMER ${ }^{1}$, S J THOMAS ${ }^{2}$, R W I COOKE ${ }^{3}$, D C LOW ${ }^{*}$, W J FYSH , $^{*}$ \\ J F MURPHY ${ }^{6}$, G M GANDY ${ }^{7}$, AND H R GAMSU ${ }^{5}$ \\ From the PHLS Communicable Disease Surveillance Centre ${ }^{1}$; Newcastle General Hospital ${ }^{2}$; Department of Child \\ Health, ${ }^{3}$ University of Liverpool; Birmingham Maternity Hospital ${ }^{4}$ King's College Hospital Medical School, ${ }^{5}$ \\ London; University of Wales, ${ }^{6}$ Cardiff; and Cambridge Health Authority (Paediatrics) ${ }^{7}$;
}

SUMMARY In a multicentre case-control study of necrotising enterocolitis risk factors were found to vary with birthweight of cases. In very low birthweight cases the risk factors identified were those associated with prolonged or recurrent hypoxia (recurrent apnoea, respiratory distress, assisted ventilation, and umbilical artery catheterisation). In heavier birthweight infants the risk factors were, in contrast, related to hypoxia at birth (low 1 minute Apgar score and endotracheal intubation at birth) and umbilical vessel catheterisation used in exchange transfusions. Contradictory findings in published case-control studies carried out in the USA may be due to differences in patient populations and management policies. Hypoxia and umbilical vessel catheterisation should still be considered as risk factors for necrotising enterocolitis.

Necrotising enterocolitis (NEC) of neonates is a relatively common and life threatening disease of unknown aetiology, characterised by necrosis of the intestinal mucosa. Specific symptoms and signs include abdominal distension, blood per rectum, and gas formation within the bowel wall. Only two epidemiological features of NEC have been well defined; both the incidence and the age of onset of disease are inversely related to gestational age and birthweight. ${ }^{1-3}$ Some studies have identified risk factors for NEC such as birth asphyxia, ${ }^{4}$ respiratory distress, ${ }^{5}$ and umbilical vessel catheterisation, ${ }^{45}$ but others have not confirmed these findings. ${ }^{6-8}$ One possible reason for this disparity is that true risk factors have been overlooked in some studies because cases of different birthweights and gestational ages have been combined in analysis; there is now evidence for the view that risk factors vary with birthweight and gestational age. ${ }^{910}$ Another possible reason is that in most studies length of stay in the unit before onset of NEC has not been controlled. If nosocomial infection has a role in the aetiology of NEC, ${ }^{11}$ length of stay may be expected to correlate with exposure to infection, and therefore with risk of NEC, but also, and independently, with other proposed risk factors such

* Present addresses: S J Thomas, The Royal Victoria Infirmary, Newcastle upon Tyne, R Cooke, Liverpool Maternity Hospital, Liverpool, D C Low, Sandwell District General Hospital, West Midlands, W J Fysh, Royal Prince Alfred Hospital, Sydney, Australia as birth asphyxia. This could lead to the false identification of "risk factors" due to the confounding effect of length of stay. In this paper we describe birthweight-specific risk factors found in a casecontrol study of NEC in which controls were matched for length of stay.

\section{Methods}

Cases of NEC were all those reported in 1981/82 as part of the UK surveillance scheme ${ }^{1}$ by eight of the collaborative centres. Only infants who developed NEC in those units were included. The definition of confirmed NEC was an illness with two of the three following features: (i) abdominal distension; (ii) blood in the stool; (iii) hypotonia and/or lethargy and/or apnoeic episodes; and, in addition, either an abdominal $x$-ray showing pneumatosis intestinalis or hepatic portal venous gas or free air in the abdomen, or histopathological evidence of NEC. Controls were selected from the same units as the index cases. In six of the eight units, two controls per case were sought, but in the remaining two units work load demands limited the study to one control per case. Controls selected were the nearest admissions to the index case whose lengths of stay were as least as long as that of the index case before onset of NEC. Since length of stay is correlated with birthweight, matching on this criterion would tend to partly control for birthweight and 
gestational age. Further matching on these two parameters was not attempted in order to simplify the study. However it was only in the $<1500 \mathrm{~g}$ case-group that there was a significant difference in birthweight between cases and controls, and this was controlled for in analysis, and the risk factors presented are independent of birthweight differences between cases and controls.

Screening of variables was first carried out by means of cross tabulations. Further analysis of a subset of variables was carried out by a conditional logistic regression model fitting approach using a computer program which allowed analysis of matched sets with a variable number of controls per case. ${ }^{12}$ This model fitting technique permitted the confounding effects of birthweight and gestational age to be controlled when estimating relative risks associated with other variables. ${ }^{13}$ Gestational age and birthweight were found to have similar confounding effects, and only results controlling for birthweight are reported. All risk factors were hypothesised to increase the risk of NEC, and therefore one-tailed $p$ values were used.

To illustrate the trends identified by the above analysis a more basic presentation of the data is included. In the group of cases $<1500 \mathrm{~g}$ birthweight and their controls, this simpler presentation is limited to those case-control sets where, by chance, the controls were also $<1500 \mathrm{~g}$. This subgroup does not have the problem of the confounding effect of birthweight differences between cases and controls and confirms the findings of analyses of the whole group in which the confounding effect of birthweight was allowed for in the modelling approach.

\section{Results}

Sixty two cases and 97 controls were included in the study. The proportions of cases and controls with the following features were similar: presentation at delivery, type of delivery, maternal anaesthesia, premature rupture of membranes, maternal antibiotics pre or postpartum, age at first enteral feeding, use of breast milk. Fifty seven per cent of cases and $53 \%$ of controls were male; $70 \%$ of cases and $64 \%$ of controls were white. In the 18 very low birthweight (VLBW) cases with umbilical artery (UA) catheters the tip of the catheter was at L2 or higher in eight, at L3 or lower in nine, and unrecorded in one. In the 15 controls with UA catheters the tip was at L2 or higher in nine, at L3 or lower in five, and not recorded in one.

CASES < 1500g BIRTHWEIGHT (VLBW) AND MATCHED CONTROLS

There were 34 cases (mean birthweight 1022g, SD= $227 \mathrm{~g}$ ) with 52 matched controls (mean birthweight $1761 \mathrm{~g}, \mathrm{SD}=840 \mathrm{~g}$ ). In the logistic regression analysis
Table 1 Estimated relative risks and lower $95 \%$ confidence intervals (one tailed) for selected variables in cases $<1500 \mathrm{~g}$ birthweight independent of birthweight effect

\begin{tabular}{lc}
\hline Variable & $\begin{array}{l}\text { Relative risk } \\
\text { (lower } 95 \% \text { confidence interval) }\end{array}$ \\
\hline I minute Apgar <6 & $0.9(0.3)$ \\
5 minute Apgar <6 & $2.2(0.4)$ \\
Endotracheal intubation & $1.9(0.6)$ \\
at birth & $7.2(1 \cdot 1)$ \\
Mechanical ventilation* & $5.4(1.4)$ \\
CPAP* & $11.4(1.9)$ \\
Recurrent apnoea* & $19.5(2 \cdot 4)$ \\
Respiratory distress* & $1 \cdot 3(0.3)$ \\
Patent ductus arteriosus & $18.1(1 \cdot 7)$ \\
UA catheter* & $3.5(0.5)$ \\
UV catheter & $0.2(0.03)$ \\
Maximum haemotocrit $>0.60$ & \\
\hline * $<0.05$ &
\end{tabular}

each of the factors listed in table 1 was examined individually while controlling for the confounding effect of birthweight differences between cases and controls. A clinical diagnosis of respiratory distress and recurrent apnoea before the onset of NEC, as well as the use of UA catheterisation, continuous positive airways pressure (CPAP), and mechanical ventilation before onset of NEC, had relative risks significantly greater than unity $(p<0.05)$. Recurrent apnoea and respiratory distress were very closely correlated, and independent effects could not be distinguished. When the correlations between recurrent apnoea and mechanical ventilation, CPAP, and UA catheterisation were examined in turn, recurrent apnoea was found to be a significant risk factor independent of the other variables. UA catheterisation, but not mechanical ventilation or CPAP, was significant once the effect of recurrent apnoea was controlled. When respiratory distress, UA catheterisation, mechanical ventilation, and CPAP were examined it was found that respiratory distress was significant independent of mechanical ventilation and UA catheterisation but not of CPAP. Neither UA catheterisation, mechanical ventilation nor CPAP was significant independent of respiratory distress. Low Apgar scores and endotracheal intubation at birth were not significant risk factors.

In order to examine the possibility that despite controlling for birthweight in the model fitting analysis there was a residual confounding effect, we separately analysed 18 of the 34 case-control sets in which the birthweights of controls were also $<1500 \mathrm{~g}$. A significantly greater proportion of these cases had UA catheterisation, recurrent apnoea, and CPAP than their $<1500 \mathrm{~g}$ controls (table 2 ). Only 2 of 18 cases did not require assisted ventilation before the onset of NEC compared with 10 of 25 controls over a similar period. The exact probabilities of the binomial distributions of these matched sets for UA 
Table 2 Data from 18 case-control sets in which birthweights of cases and controls were $<1500 \mathrm{~g}$

\begin{tabular}{lcc}
\hline Variable & $\begin{array}{l}\text { Cases }(\%) \\
(n=18)\end{array}$ & $\begin{array}{l}\text { Controls }(\%) \\
(n=25)\end{array}$ \\
\hline $\begin{array}{l}\text { Mean birthweight } \\
\text { (standard deviation) }\end{array}$ & $972 \mathrm{~g}(245 \mathrm{~g})$ & $1093 \mathrm{~g}(265 \mathrm{~g})$ \\
1 minute Apgar <6 & $9(50)$ & $10(40)$ \\
5 minute Apgar <6 & $3(17)$ & $1(4)$ \\
Endotracheal intubation & $13(72)$ & $14(56)$ \\
at birth & $15(83)$ & $14(56)$ \\
Mechanical ventilation & $13(72)$ & $7(28)$ \\
CPAP & $14(78)$ & $7(28)$ \\
Recurrent apnoea & $17(94)$ & $13(52)$ \\
Respiratory distress & $2(11)$ & $10(40)$ \\
No assisted ventilation & $10(56)$ & $10(44)$ \\
Patent ductus arteriosus & $14(78)$ & $2(8)$ \\
UA catheter & $3(17)$ & $4(16)$ \\
UV catheter & $1(5)$ & \\
Maximum haematocrit $>0.60$ & \\
\hline
\end{tabular}

catheterisation were 0.012 , for recurrent apnoea 0.0025, and for CPAP 0.012. The independent effects of recurrent apnoea and UA catheterisation indicated in the model fitting analysis were supported by the trends found in this subgroup; 12 of the 14 cases with recurrent apnoea also had a UA catheter compared with only 2 of 7 controls. Twelve of 14 cases with UA catheters had recurrent apnoea compared with only 2 of 11 controls.

CASES $\geq 1500 \mathrm{~g}$ AND $\geq 2000 \mathrm{~g}$, BIRTHWEIGHT AND MATCHED CONTROLS

There were 28 cases (mean birthweight $2342 \mathrm{~g}$, SD $690 \mathrm{~g}$ ) of birthweight $\geq 1500 \mathrm{~g}$ and 45 matched controls (mean birthweight 2396g, SD 969g). Though cases and controls were of similar mean birthweight this factor was nevertheless included in model fitting. Endotracheal intubation, mechanical ventilation, UA catheterisation, UV catheterisation, and exchange transfusion had relative risks significantly greater than unity $(p<0.05)$ independent of birthweight (table 3$)$.

Table 3 Estimated relative risks and lower 95\% confidence intervals (one tailed) for selected variables in cases $\geq 1500 \mathrm{~g}$ birthweight independent of birthweight effect

\begin{tabular}{ll}
\hline Variable & $\begin{array}{l}\text { Relative risk } \\
\text { (lower } 95 \% \text { confidence interval) }\end{array}$ \\
\hline 1 minute Apgar <6 & $2.3(0.9)$ \\
5 minute Apgar <6 & $4 \cdot 1(0.6)$ \\
Endotracheal intubation & $3.4(1 \cdot 3)$ \\
at birth* & $3.9(1 \cdot 2)$ \\
Mechanical ventilation* & $2 \cdot 7(0.9)$ \\
CPAP & $3.5(0.9)$ \\
Recurrent apnoea & $0.8(0.3)$ \\
Respiratory distress & $5 \cdot 1(1.5)$ \\
UA catheter* & $8.9(1.4)$ \\
UV catheter* & $6.1(1.6)$ \\
Exchange transfusion* & \\
\hline *p<0.05 &
\end{tabular}

Low Apgar scores, CPAP, recurrent apnoea, and respiratory distress were not significant risk factors, although for the first three of these variables small numbers may have accounted for this. In a model consisting of UA catheterisation, UV catheterisation, and exchange transfusion, independent effects were not observed. Other factors could not be analysed in the modelling because of small numbers. The proportions of cases and controls with factors of interest are given in table 4.

Of the 28 cases $\geq 1500 \mathrm{~g}$ birthweight, 16 were $\geq 2000 \mathrm{~g}$ (mean $2764 \mathrm{~g}$, SD 631g) with 26 controls (mean $2529 \mathrm{~g}$, SD $1088 \mathrm{~g}$ ). In this subgroup 1 minute Apgar score $<6$ and intubation at birth were significant risk factors at the $5 \%$ level (table 5), but these were not independent of one another. Mechanical ventilation and umbilical catheterisation were not significant risk factors, but this may be due to small numbers.

\section{Discussion}

Hypotheses about the pathogenesis of NEC have focused on the role of bowel ischaemia in relation to enteric feeding, and the roles of specific bacteria and viruses. ${ }^{11}$ Kosloske ${ }^{14}$ has proposed that NEC is the result of a combination of intestinal ischaemia, colonisation by pathogenic bacteria, and excess

Table 4 Selected data from cases $>1500 \mathrm{~g}$ birthweight and controls

\begin{tabular}{lcc}
\hline Variable & Cases (\%) & Controls (\%) \\
\hline 1 minute Apgar <6 & $17 / 28(61)$ & $18 / 45(40)$ \\
5 minute Apgar <6 & $5 / 26(19)$ & $3 / 37(8)$ \\
Endotracheal intubation & $13 / 28(46)$ & $10 / 45(22)$ \\
at birth & $11 / 28(39)$ & $9 / 45(20)$ \\
Mechanical ventilation & $8 / 27(30)$ & $7 / 43(16)$ \\
CPAP & $7 / 28(25)$ & $5 / 45(11)$ \\
Recurrent apnoea & $13 / 28(46)$ & $24 / 45(53)$ \\
Respiratory distress & $12 / 28(43)$ & $8 / 45(18)$ \\
UA catheterisation & $6 / 27(22)$ & $2 / 42(5)$ \\
UV catheterisation & $7 / 27(26)$ & $2 / 43(5)$ \\
Exchange transfusion & &
\end{tabular}

Table 5 Estimated relative risks and lower $95 \%$ confidence intervals (one tailed) for selected variables in cases $\geq 2000 \mathrm{~g}$ birthweight

\begin{tabular}{ll}
\hline Variable & $\begin{array}{l}\text { Relative risk } \\
\text { (lower } 95 \% \text { confidence interval) }\end{array}$ \\
\hline I minute Apgar $<6^{*}$ & $3.4(1 \cdot 1)$ \\
Endotracheal intubation & $4 \cdot 7(1 \cdot 2)$ \\
at birth* & $3 \cdot 2(0 \cdot 8)$ \\
Mechanical ventilation & $3 \cdot 5(0 \cdot 8)$ \\
UA catheter & $6.3(1 \cdot 0)$ \\
UV catheter & \\
\hline
\end{tabular}

$* \mathrm{p}<0.05$ 
protein substrate in the intestinal lumen. Evidence for an infective aetiology of NEC is inconclusive as yet, although the occurrence of cases in outbreaks which can be terminated by control of infection measures is suggestive. ${ }^{15}$ Support for the role of bowel ischaemia comes from studies which have identified risk factors such as birth asphyxia ${ }^{4}$ and umbilical vessel catheterisation ${ }^{45}$ which may be expected to induce bowel ischaemia in some circumstances, and from one recent study which found an association between reduced aortic blood flow in the growth retarded fetus and subsequent development of NEC. ${ }^{16}$ However, other studies have produced conflicting results. ${ }^{6-8}$

One possible reason for the discrepancy between studies is that risk factors may vary with birthweight and gestational age, as suggested by Wilson et al. ${ }^{10}$ This was confirmed in our study in which controls were matched for length of stay. In VLBW cases the risk factors identified were recurrent apnoea, respiratory distress, CPAP, mechanical ventilation, and UA catheterisation. The association of NEC with assisted ventilation could be explained by their use in the management of recurrent apnoea, and to some extent with respiratory distress. UA catheterisation is commonly used in the management of prolonged respiratory problems, but its association with NEC appeared to be independent of recurrent apnoea, though not of respiratory distress. The occurrence of birth asphyxia (indicated by low Apgar scores and endotracheal intubation at birth) did not significantly increase the risk of NEC. These findings could not be explained by birthweight differences between cases and controls since this was controlled in the analysis, and the observations were confirmed in a subgroup in which controls were, by chance, also $<1500 \mathrm{~g}$.

In cases who weighed $\geq 2000 \mathrm{~g}$ at birth, recurrent apnoea and respiratory distress were rarely diagnosed, and these problems, and also assisted ventilation, were not significantly associated with NEC. A low 1 minute Apgar score and endotracheal intubation were significant risk factors. When all cases $\geq 1500 \mathrm{~g}$ were considered, mechanical ventilation was significant. In addition, there was a significantly increased risk associated with umbilical vessel catheterisation and exchange transfusion.

In summary, the risk factors identified fell into two groups: those related to respiratory problems and those associated with umbilical vessel catheterisation. As birthweight increased respiratory risk factors shifted from variables associated with prolonged respiratory difficulties, ie, recurrent apnoea and respiratory distress, to those associated with birth asphyxia. Umbilical artery catheterisation was shown to be a risk factor in smaller infants, but this could be explained by its use in the management of respiratory distress. In larger infants UA catheterisation was associated with exchange transfusions and was a risk factor independent of respiratory problems.

The findings of our study are in broad agreement with the two previous UK case-control reports ${ }^{45}$ as well as with one from Canada, ${ }^{17}$ although in these studies the interdependence of variables was not examined. Bunton et al, ${ }^{4}$ in a series of cases most of whom were of over $1500 \mathrm{~g}$ birthweight, identified birth asphyxia (1 minute Apgar $<5,5$ minute Apgar $<7$ or intubation and ventilation for $>10$ minutes) and also the use of umbilical vessel catheters as significant risk factors. Hyaline membrane disease was reported not to differ significantly between cases and controls. though using the published figures $a \chi^{2}$ of $6.26(\mathrm{p}=$ 0.012 ) by the Pike and Morrow test for matched sets was the estimate closest to the null hypothesis that would be possible. Smith et al,,$^{5}$ in an outbreak in which 10 of 17 cases were $>1500 \mathrm{~g}$, identified apnoea, umbilical artery catheterisation, idiopathic respiratory distress syndrome, intermittent positive pressure ventilation, and pneumonia as risk factors. Yu et al, ${ }^{16}$ in a Canadian unit, examined risk factors within birthweight groups and found in VLBW infants that recurrent apnoea (although this is not referred to in a later review $^{8}$ ), hypertonic feeding, and a moderately depressed 1 minute Apgar score were significantly associated with NEC, but hyaline membrane disease and umbilical catheterisation were not. In infants of $1500-2499 \mathrm{~g}$ birthweight and 1 minute Apgar score of $<4$, shock and exchange transfusions were significant risk factors, but recurrent apnoea, hyaline membrane disease, and umbilical artery catheterisation were not. Our study supports the association with recurrent apnoea in VLBW infants, and low 1 minute Apgar score and exchange transfusion in heavier birthweight infants.

Doubt has been cast on the role of bowel ischaemia in NEC by three large studies which did not identify associated risk factors. ${ }^{6-8} \mathrm{Kliegman}$ et $a l^{7}$ investigated VLBW infants admitted to one unit in the USA over four years and found only abruptio placenta to be a significant risk factor. Indeed, cases of NEC had a lower incidence of apnoea, umbilical artery catheterisation, and respiratory distress syndrome than controls. A smaller study by Wilson et al also failed to identify ischaemic risk factors in VLBW infants. In larger infants, hypoglycaemia and respiratory distress were commoner in cases than in controls. ${ }^{10}$ From Australia Yu et al ${ }^{\beta}$ reported a similar study of VLBW infants, also with mainly negative findings. A large multicentre study of infants of $<1750 \mathrm{~g}$ failed to identify risk factors other than low birthweight and maternal toxaemia during pregnancy (a negative correlation) but the factors evaluated in this study did not include recurrent apnoea, assisted ventilation or UA catheterisation. ${ }^{18}$ They did evaluate 
low Apgar score, and delivery room resuscitation with negative results, but we found these to be significant only in infants of $\geq 1500 \mathrm{~g}$ birthweight.

Such discrepancies in those risk factors identified by different authors are puzzling but not necessarily inconsistent with the hypothesis that ischaemia of the gut might have an aetiological role. We do not know the precise relation between bowel ischaemia and variables such as birth asphyxia or hyaline membrane disease, and bowel ischaemia may possibly occur in the absence of identified risk factors. We have no means as yet of directly measuring the injury to the bowel nor the extent of ischaemia, though the finding of reduced aortic blood flow in the fetus as a response to hypoxia suggests a causal mechanism for bowel ischaemia and subsequent NEC. ${ }^{16}$ It is possible that differences in the incidence and management of respiratory disorders between patient populations may produce conflicting results despite a common aetiology of NEC. In support of this contention it may be noted that there is a great variation in incidence of risk factors in the control populations appearing in other reports. For example, in the study of Kliegman et $a l^{7} 75 \%$ of VLBW controls had UA catheters; in the Australian study ${ }^{8}$ the figure was $70 \%$. However only $40 \%$ of VLBW controls in our study had UA catheters, and in the Canadian study of Yu et al $^{17}$ the figure was $39 \%$. The incidence of patent ductus arteriosus in controls was only $12 \%$ in the study of $\mathrm{Yu}$ et al $^{17}$ but in the later Australian study ${ }^{8}$ it was $43 \%$. There were other significant differences between study control populations which emphasise the caution that should be exercised when comparing results from different studies. Future studies should focus on the dynamics and interactions of risk factors. Attention should also be given to developing more direct measures of gastrointestinal perfusion.

We believe that our results confirm that it is prudent to manage neonates on the basis that hypoxia and umbilical vessel catheterisation may contribute to the pathogenesis of NEC.

We thank our clinical colleagues in the British Association for Perinatal Paediatrics for their support of this study, in particular, Dr Peter Dunn, Dr Brian Speidel, Dr Cliff Roberton, Dr D W A Milligan, and Professor O P Gray. We thank Dr J Lubin for providing the computer program and Dr Nancy Hargrett, CDC Atlanta, USA, and Dr Hillary Tillett, CDSC , London, for considerable statistical advice and support.

\section{References}

${ }^{1}$ British Asociation for Perinatal Paediatrics and PHLS Communicable Disease Surveillance Centre. Surveillance of necrotising enterocolitis, 1981-2. Br Med J 1983; 287, 824-6.

2 Wilson R, Kanto WP, McCarthy BJ, Burton A, Lewin P, Terry J, Feldman RA. Epidemiologic characteristics of necrotising enteroclitis: a population-based study. Am J Epidemiol 1981; 114, 880-7.

${ }^{3}$ Wilson R, Kanto WP, McCarthy BJ, Burton A, Lewin P, Feldman RA. Short communication. Age at onset of necrotising enterocolitis: an epidemiologic analysis. Paediat Res 1982; 16, 82-4.

4 Bunton GL, Durbin GM, McIntosh N, Shaw DG, Taghizadeh A, Reynolds EOR, Rivers RPA, Urman G. Necrotising enterocolitis, controlled study of 3 years' experience in a neonatal intensive care unit. Arch Dis Child 1977; 52, 772-7

${ }^{5}$ Smith MF, Borriello SP, Clayden GS, Casewell MW. Clinical and bacterial findings in necrotising enterocolitis: a controlled study. $J$ Infect $1980 ; 2,23-31$.

${ }^{6}$ Stoll JB, Kanto WP, Glass RI, Nahmias AJ, Brann AW. Epidemiology of necrotising enterocolitis: A case control study. J Pediat 1980; 96, 447-51.

${ }^{7}$ Kliegman RM, Hack M, Jones P, Fanaroff AA. Epidemiologic study of necrotising enterocolitis among low-birthweight infants. $J$ Pediat $1982 ; 100,440-4$.

${ }^{8}$ Yu VYH, Joseph R, Bajuk B, Orgill A, Astbury J. Perinatal risk factors for necrotising enterocolitis. Arch Dis Childh $1984 ; 59,430-4$.

${ }^{9}$ Wilson R, Kanto WP, McCarthy BJ, Feldman RA. Age at onset of necrotising enterocolitis. Risk factors in small infants. Am J Dis Child 1982; 136, 814-6.

10 Wilson R, del Portillo M, Schmidt E, Feldman RA, Kanto WP. Risk factors for necrotising enterocolitis in infants weighing more than $2000 \mathrm{gms}$ at birth: a case-control study. Paediatrics 1983; 71, 19-22.

11 Kliegman RM. Neonatal necrotising enterocolitis: implications for an infectious disease. Paediat Clin $N$ Amer 1979; 26, 2, 327-44.

12 Lubin JH. A computer program for the analysis of matched case-control studies. Comput Biomed Res 1981; 14, 138-43.

13 Breslow NE, Day NE. Statistical methods in cancer research. Volume 1 -the analysis of case-control studies. IARC scientific publications no. 32. WHO International Agency for Research on Cancer 1980; Lyon, 248-79.

14 Kosloske AM. Pathogenesis and prevention of necrotising enterocolitis: A hypothesis based on personal observation and a review of the literature. Pediatrics 1984; 74, 1086-92.

${ }^{15}$ Book LS, Overall JC, Herbst JJ, et al. Clustering of necrotising enterocolitis: Interruption of infectioncontrol measures. New Engl J Med 1977; 297, 984-6.

16 Hackett GA, Campbell S, Gamsu H, Cohen-Overbeek T, Pearce JMF. Doppler studies in the growth retarded fetus and prediction of neonatal necrotising enterocolitis, haemorrhage and neonatal morbidity. Br Med J 1987, 294, 13-16.

$17 \mathrm{Yu}$ VYH, Tudehope DI. Neonatal necrotising enterocolitis: 2 perinatal risk factors. Med J Aust 1977, 1, 688-93.

${ }^{18}$ Kanto WP Jr, Wilson R, Breart GL, Zierler S, Purolit DM, Peckham GJ, Ellison C. Perinatal events and necrotising enterocolitis in premature infants. Am J Dis Child 1987, 141, 167-9. 